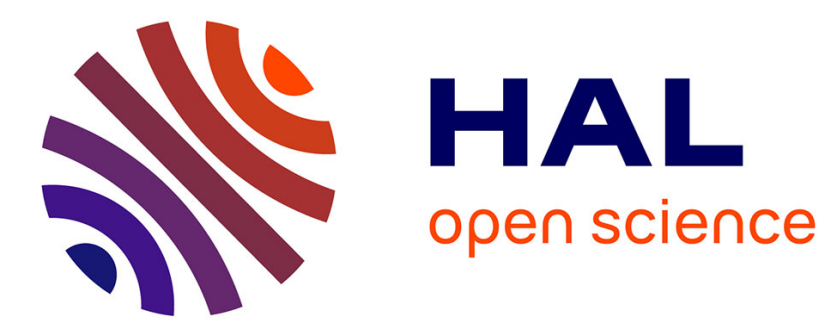

\title{
Snecma's Viewpoint on the Numerical and Experimental Simulation of Blade-Tip/Casing Unilateral Contacts
}

Antoine Millecamps, Alain Batailly, Mathias Legrand, François Garcin

\section{To cite this version:}

Antoine Millecamps, Alain Batailly, Mathias Legrand, François Garcin. Snecma's Viewpoint on the Numerical and Experimental Simulation of Blade-Tip/Casing Unilateral Contacts. ASME Turbo Expo Conference, ASME, Jun 2015, Montréal, Canada. 10.1115/GT2015-42682 . hal-01223582

\section{HAL Id: hal-01223582 \\ https://hal.science/hal-01223582}

Submitted on 3 Nov 2015

HAL is a multi-disciplinary open access archive for the deposit and dissemination of scientific research documents, whether they are published or not. The documents may come from teaching and research institutions in France or abroad, or from public or private research centers.
L'archive ouverte pluridisciplinaire HAL, est destinée au dépôt et à la diffusion de documents scientifiques de niveau recherche, publiés ou non, émanant des établissements d'enseignement et de recherche français ou étrangers, des laboratoires publics ou privés. 


\title{
Snecma's viewpoint on the numerical and experimental simulation of blade-tip/casing unilateral contacts
}

\author{
Antoine Millecamps ${ }^{a}$, Alain Batailly ${ }^{b}$, Mathias Legrand ${ }^{b}$, François Garcin ${ }^{a}$
}

\begin{abstract}
Aircraft engine manufacturers are developping a new generation of turbojet engines featuring a lower impact on the environment, increased performances as well as reduced gas consumption. The efficiency of an engine is mostly driven by the operating clearance between the rotating parts and the stator. Accordingly, modern designs focus on the minimization of these clearances. In this context, unavoidable rotor imbalances or mistuning stemming from manufacturing processes as well as distortions resulting from thermal expansion or assembly conditions may generate blade-tip/casing contacts that are now considered as non-accidental operating conditions. In order to minimize the consequences of such events, an abradable coating is sprayed along the inner surface of the casing and acts as a fuse when the blade and the casing are in contact. However, even when an abradable coating is used, significant structural damages and wear as well as blade failures have been witnessed experimentally. The understanding of the physical phenomena at play called, on one hand, for throrough experimental investigations of rotor/stator contacts on full-scale stages of compressors and underlined that blade failure is mainly due to vibratory fatigue although the abradable coating is worn. On the other hand, numerical simulations have been performed to better understand the blade dynamics: over the last decade Snecma and its academic partners jointly developed a code for the simulation of COntacts between ROtor and Stator: COROS. This code allows for the simulation of contacts-with a Lagrange multiplier contact treatment procedure — between full 3D models of engine components and accounts for abradable coating material removal. In particular, the simulation of experimental set-ups with COROS highlighted the correlation between the blade vibratory response and the abradable material removal. Yet still an experimental code, this paper addresses the integration of COROS within the design process of aircraft engine blades at Snecma. The paper focuses on on-going research for the identification of critical parameters in the arising of interactions as early as the design stage of components. A particular attention is paid to the mechanical properties of the abradable coating for which both experimental and numerical investigations are detailed.
\end{abstract}

\section{Keywords}

Turbomachinery, unilateral contact and friction, nonlinear dynamics, rotor-stator interactions, design process

a Snecma Site de Villaroche, Moissy-Cramayel, 77550, France

b Structural Dynamics and Vibration Laboratory, McGill University, 817 Sherbrooke West, H3A 0C3, Montréal, Québec, Canada

\section{Introduction}

Competition between engine manufacturers, high gas prices and stringent environmental regulations yield tight market conditions for the development of a new generation of aircraft engines. In this context, novel engines must achieve higher performances and lower gas consumption in order to maximize their energy efficiency. Such maximization is typically twofold, it may be achieved by: (1) using lighter materials such as composite materials and (2) reducing parasitic leakage flows. The latter are closely related to the operating clearances between rotating and stationary components of an engine, they have a direct impact over the flow compression ratio from a stage of the engine to another and thus critically affects the overall engine efficiency. Theoretically, the reduction of parasitic leakage flows is achieved through the closing of operating blade-tips/casing clearances. In practice however, the minimization of operating clearances leads to more frequent structural contacts between the engine components and such events are now accepted as normal operating conditions. Because the physical phenomena at play during these contacts are still mostly unelucidated, many investigations have been recently carried out $[1,2,3]$. In order to mitigate the consequences of these structural contacts over the components structural integrity, a widely used solution consists of depositing an abradable coating along the casing circumference, see Fig. 1. These abradable coatings are generally laid by plasma spraying of composite powders, comprising a metal base (aluminium and silicon) and a polymer filler (polyester) generating porosities. The mechanical properties of these coatings are singular as they must satisfy the following compromise: an abradable coating should be resilient enough in order not to be damaged by the gas flow while it should act as a sacrificial material when an impact with the rotating blade occurs. The abradable microstructures are known to feature good cohesionthanks to the metal matrix - and good abrasion-thanks to the polyester and porosities $[4,5]$.

Nevertheless, experimental observations following rotor/stator

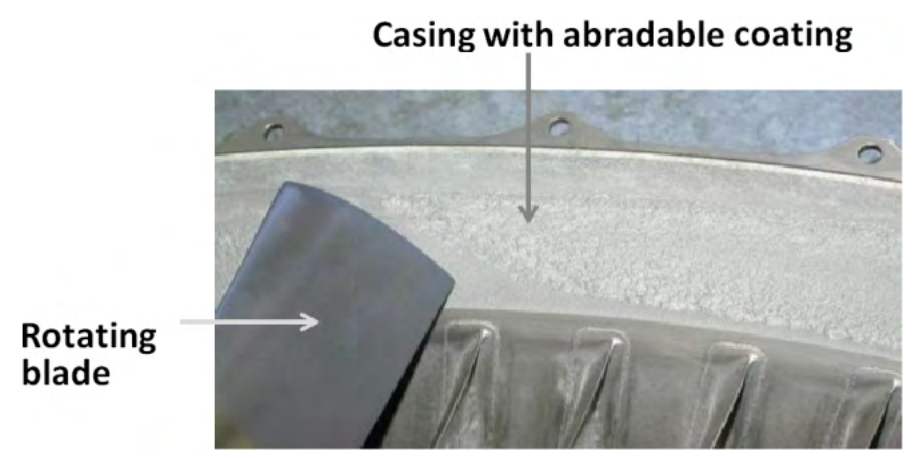

Figure 1. Overview of a rotating blade and the abradable coating on the inner face of casing

interaction simulations on full scale test benches revealed that significant damages may appear both on the blade, see cracks in Fig. 2, and the abradable coating. The critical need for ensuring
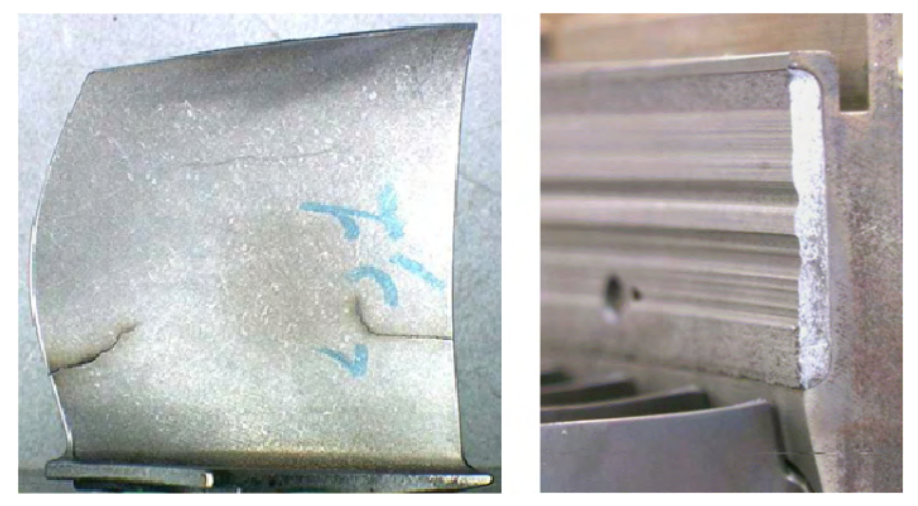

Figure 2. Important damages on titanium blades and wear profile on abradable coating

structural integrity of the engine components combined with the 
necessity of maintaining a higher engine efficiency was the core motivation for Snecma to initiate research projects and collaborations focusing on the numerical and experimental simulation of rotor/stator interactions. First, an experimental test bench has been developped in order to simulate rotor/stator interactions on a full scale low-pressure compressor under vacuum with an abradable coating deposited along the casing circumference [6]. Simultaneously, a research program focused on the development of a numerical strategy [7] for the simulation of such interactions. The goal of the research program was to develop a numerical strategy accurate enough to predict experimental results and that could be integrated within Snecma's industrial environment as a first step toward the inclusion of structural contacts within the design process of compressor and turbine blades. The need for such numerical strategy called for the development of a dedicated in-house code as commercial softwares could not provide satisfying results due to several limitations such as the impossibility to combine the use of efficient component mode synthesis methods with a precise contact treatment procedure (respect of non-penetration conditions between structures) and accounting for both centrifugal and gyroscopic effects. In addition, strategies for the modeling of the abradable removal are currently non-existent in commercial softwares.

This paper aims at describing the strategy adopted by Snecma for acquiring knowledge on rotor/stator interactions initiated by blade-tip/casing or abradable coating contacts. First of all, the experimental test benches developped for the simulation of rotor/stator interactions are introduced. During the last ten years two series of tests were performed and their main results are presented herein. Secondly the original numerical approach, namely COROS, used at Snecma to study the contact between rotating part and casing is briefly detailed. Then, applications of COROS for the simulation of industrial cases are reviewed. Finally, the paper deals with on-going Research and Development projects following two guidelines: (1) the characterization of abradable materials and (2) the numerical improvement of COROS.

\section{Experimental simulations}

For the sake of confidentiality, the two experimental tests are referred to as $\mathrm{SN}_{1}$ and $\mathrm{SN}_{2}$, also, all results are normalized. Test benches $\mathrm{SN}_{1}$ and $\mathrm{SN}_{2}$ respectively involve a full scale lowpressure compressor stage and a full scale high-pressure compressor stage. Accordingly, the blade designs are significantly different and so are the mechanical properties of the abradable coatings used for each test. Obviously, targetted angular speeds are also different in agreement with the nominal angular speed range of the stage of interest. For both test benches, one of the blade is slightly longer and is instrumented with strain gages sensitive to the blade first bending and torsional free vibration modes. Accelerometers are located on the casing. Contact with the surrounding casing is thus initiated on this longer blade as centrifugal loads are applied as the bladed disk angular speed increases. The casing is not deformed, though its shape is not perfectly circular due to manufacturing tolerances and assembly conditions yield a slight ovalization. The cold clearance between rotor and stator is zero. For each configuration the rotor speedup aims at reaching an angular speed for which the blade vibration along its first bending mode is synchronous. Also, it should be mentioned that tests are performed under vacuum, thus there are no aerodynamic loads.

\subsection{Test bench $\mathrm{SN}_{1}$}

This test bench is presented in detail in [6]. The geometries of parts (casing and blades) are representative of a low-pressure compressor. The targetted angular speed $\Omega_{1}$ is chosen so that it corresponds to a sixth of the first eigenfrequency of the blade as depicted on the Campbell diagram in Fig. 3. For $\Omega=\Omega_{1}$, the first eigenfrequency of the blade intersects the sixth engine order line H6. Accordingly, when contact occurs, it is expected that the blade will mostly respond on its first free-vibration mode, the first bending mode.

At the end of the experimental simulation, cracks, heating marks and damages at the tip are witnessed on the blade. Also, a significant wear is observed on the abradable coating following a six-lobe pattern along the casing circumference as depicted in Fig. 4. Additionally, thermocouples located on the outer side of casing show significant increase of temperature, about $+50{ }^{\circ} \mathrm{C}$. Interestingly, the accelerometers on the casing did not show any significant levels of vibration.

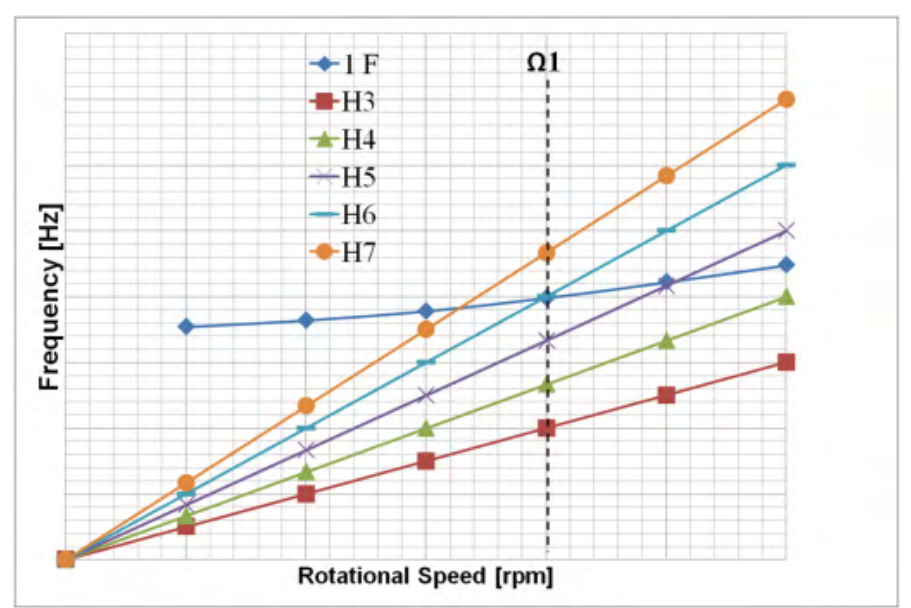

Figure 3. First natural frequency of the blade (a stiff disk is assumed) over the angular speed range of interest and engine order lines $\mathrm{H} 3$ to $\mathrm{H} 7$. The first eigenfrequency of the blade $(-)$ intersects the sixth engine order line H6 ( - ).

Based on the results obtained with test bench $\mathrm{SN}_{1}$, it is first highlighted in [6] that blade failure is observed following a blade/abradable coating interaction. The failure seems to be induced by vibratory fatigue since the blade strain gages bring to light the increase of the stress amplitude within the blade during the interaction. An extensive post-processing procedure based on a Fourier Transform of the results revealed that the first bending mode is dominant in the blade dynamics, particularly at the end of the interaction. As mentioned above, the blade dynamics along its first bending mode is synchronous with the angular speed and the number of lobes found around the casing circumference is in agreement with the targetted engine order H6. In addition, this test bench provides useful data regarding thermal effects within the abradable coating that may be related to the wear pattern.

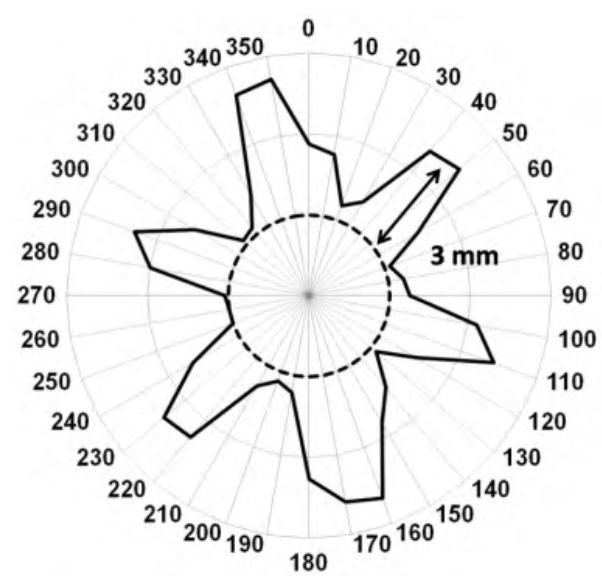

Figure 4. Circumferential wear of the abradable coating, facing the blade trailing edge. Dashed circles represent the initial radius 


\subsection{Test bench $\mathrm{SN}_{2}$}

Test bench $\mathrm{SN}_{2}$ involves a high-pressure compressor stage. The abradable coating composition contains much less polyester than for test bench $\mathrm{SN}_{1}$, it is representative of a coating sprayed within a high-pressure compressor stage. Similarly to test bench $\mathrm{SN}_{1}$, the targetted angular speed $\Omega_{2}$ is chosen so that blade vibration along its first bending free-vibration mode is synchronous. It is pictured in Fig. 5 that for $\Omega=\Omega_{2}$, the first eigenfrequency intersects the eigth engine order line $8 \mathrm{~N}$. For the considered blade design, the angular speed $\Omega_{2}$ is of particular interest as it is also the location of the intersection between the first torsional mode and the twenty second engine order line $22 \mathrm{~N}$. The concomitance of both intersections motivates the experimental simulations carried out around this interaction point.

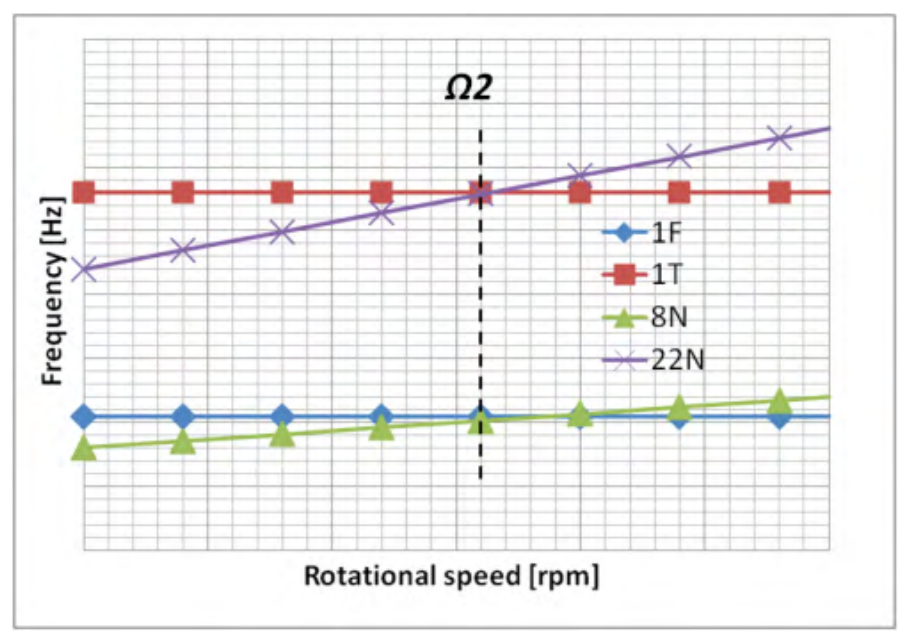

Figure 5. First and second natural frequencies of the blade (bending and torsional mode) depending on speed. First eigenfrequency (-); eigth engine order line $8 \mathrm{~N}(-)$; first torsional mode $(-)$; twenty second engine order line $22 \mathrm{~N} \mathrm{(-)}$

Post-interaction observations did not reveal any blade failure: no significant damage could be seen on the longer blade eventhough stress signals time histories acquired by the different strain gages featured increasing stress levels and peaks of stresses as visible in Fig. 6. As opposed to what was observed with test bench $\mathrm{SN}_{1}$, the thermocouples located on the outer surface of the casing did not feature significant temperature variations (more or less $2^{\circ} \mathrm{C}$ through out the simulation). Regarding the abradable coating wear pattern, twenty-two lobes are noticeable, thus indicating that the torsional interaction may have been dominant.

A Fourier analysis of the stress signal history is conducted for three different time intervals as depicted in Fig. 6. This analysis reveals that the first bending mode $(1 \mathrm{~F})$ is mostly dominant at the beginning of the interaction while the peak of stress located around $t_{2}$ almost solely involves the first torsional mode (1T). Following the stress peak, for $t=t_{3}$, both the first bending mode and the first torsional mode are significantly involved in the blade dynamics One may speculate that the concomitance of two intersections involving distinct free-vibration modes mitigates the possibility of the interaction thus explaining why, contrary to test bench $\mathrm{SN}_{1}$, no blade failure is observed in test bench $\mathrm{SN}_{2}$.

\section{Numerical strategy and integration within snecma industrial environment}

As mentioned in the introduction, the research project carried out by Snecma aims at the development of a numerical strategy, namely COROS, dedicated to the modeling of the test benches presented in the previous section. The numerical strategy must comply with the following specifications:
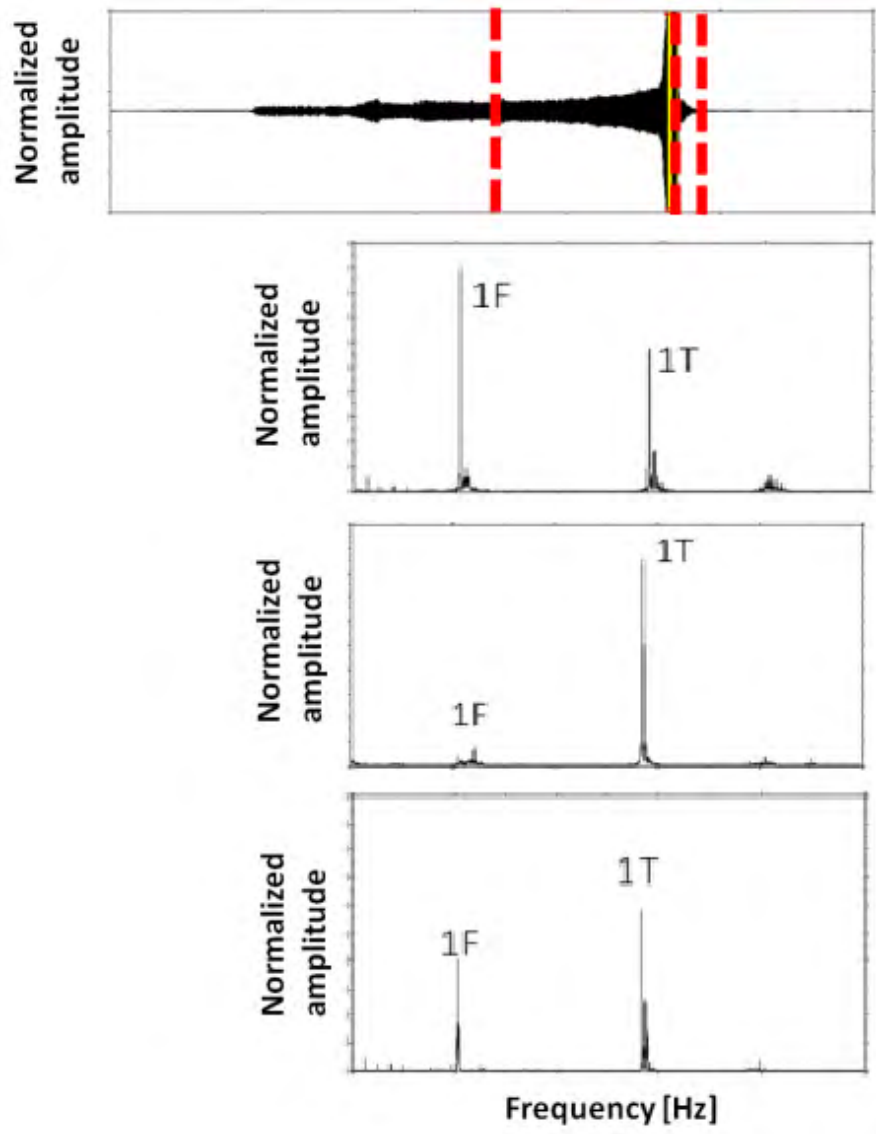

Figure 6. Time evolution of strain gage signal and the FFT analysis at three different time

- be numerically efficient: the blade vibratory behaviour must be retrieved for many revolutions for potentially many angular speeds and contact configurations,

- allow for retrieving displacement and stress fields over the full finite element model at any time step of the simulation,

- account very accurately for non-penetration contact conditions between the structures involved in the interaction,

- be able to simulate a large variety of contact configurations (casing shape, clearance configuration...),

- account for both centrifugal and gyroscopic effects,

- be fully compatible with the Snecma industrial environment.

\subsection{Solution method}

Because the physical phenomena at play during the interaction are not fully understood, a quantitative approach based on explicit time integration is considered: the central finite differences time integration scheme is employed. Frequency based approaches, that typically require an a priori knowledge of the physical phenomena-in order to properly select useful harmonics for instance-are thus excluded. The need for a precise contact treatment procedure motivates the use of a Lagrange-multiplier based approach [8] instead of a penalty-based method which inconveniently allows for significant residual penetrations. In order to ensure the computational efficiency of the procedure, component mode synthesis methods are used and lead to small yet accurate models of full 3D finite element models. Fixed-interface methods are preferred [7] as they allow for keeping selected degrees of freedom useful for contact management along the blade tip within the reduced space. Finally, a wear law is developped [9] in order to model abradable coating removal as well as the contact forces applied along the blade tip during the interaction.

The reader may refer to previous publications for additional details regarding the convergence of the obtained results with respect 
to the time step, the modal reduction basis or the discretization of the abradable coating.

\subsection{Industrial integration}

In order to ensure a full integration of the numerical strategy within Snecma industrial environment, the input finite element modes are industrial 3D finite element models obtained from Samcef. The output result files are written in such way they can be read by Samcef post-processing modules: Samres and Samfac. A dedicated graphic user interface is created and advanced postprocessing tools (interaction maps, automated Fourier analyses, wear maps...) are created with Python codes.

\section{Numerical results}

\subsection{Test bench $\mathrm{SN}_{1}$}

The results obtained with numerical model of test bench $\mathrm{SN}_{1}$ have been published in [10]. The proposed numerical strategy was successfully used for the determination of the interaction angular speed. The abradable wear pattern along the casing circumference-featuring six distinct lobes depicted in Fig. 7-as well as the frequency content of the blade dynamics were accurately predicted. In addition, predicted maximum stress areas within the blades were in good agreement with experimentally observed damaged areas.

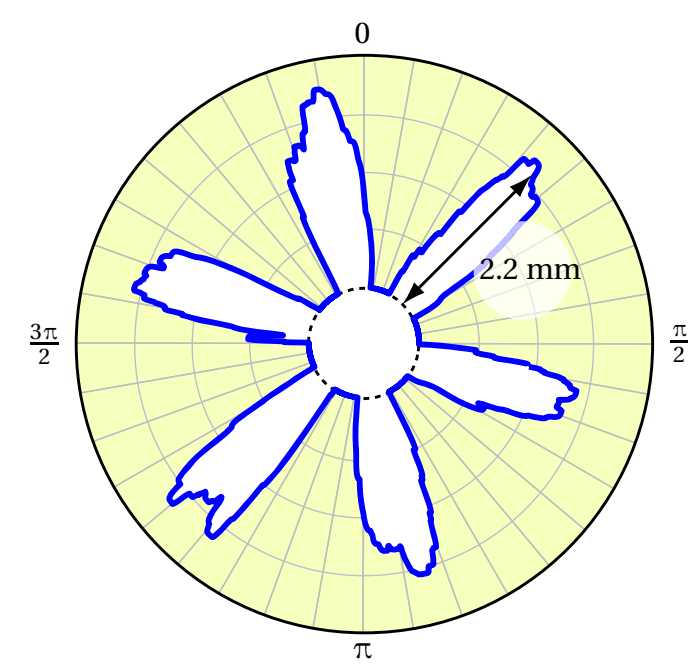

Figure 7. Wear pattern of the abradable coating (facing the trailing edge) simulated with COROS [10] for test bench $\mathrm{SN}_{1}$

\subsection{Test bench $\mathrm{SN}_{2}$}

A numerical model was also considered for test bench $\mathrm{SN}_{2}$. Contrary to test bench $\mathrm{SN}_{1}$, the ovalization of the casing was less obvious experimentally. Yet, an ovalized casing was used in the numerical model in order to initiate contact with the rotating blade. Based on empirical data, the wear law mechanical properties were updated in order to account for the specificity of the abradable coating of this test bench. A 22-lobe wear pattern pictured in Fig. 8 was numerically predicted in agreement with experimental observations. However, the numerical model failed to predict comparable participations of the first bending and torsional modes within the blade dynamics. Contrary to the numerical results obtained for test bench $\mathrm{SN}_{1}$, results for $\mathrm{SN}_{2}$ were particularly sensitive to the casing initial profile thus hinting that the phenomenon of interest may not be as robust as for test bench $\mathrm{SN}_{1}$.

\subsection{Optimization of a blade design}

Recently, COROS was integrated to the design process of a highpressure compressor blade [11]. The design improvement was

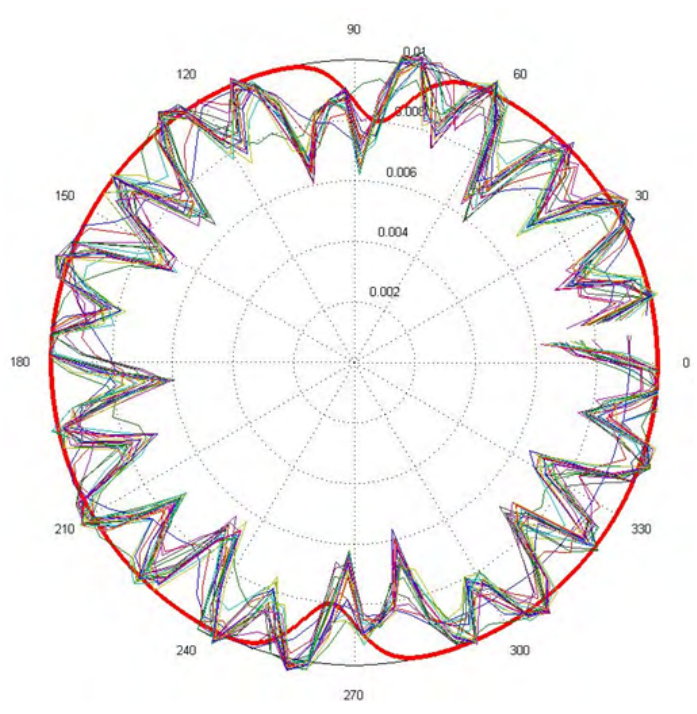

Figure 8. Wear pattern of the abradable coating (facing 8 points: from trailing to leading edge) simulated with COROS for test bench $\mathrm{SN}_{2}$ superimposed with the initial casing profile ( $(-)$

driven by aerodynamic performances. The design parameter was the stacking law, see Fig. 9, as well as the cross section of the blade. The stacking law of a blade is a fictive line, from the root to the edge of a blade, giving the direction and the orientation of the stack of cross section.

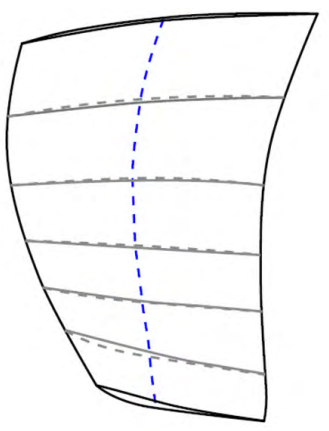

(a)

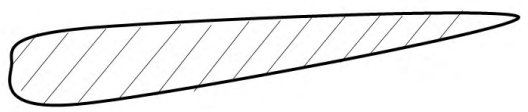

(b)
Figure 9. (a) Schematic view of the stacking law of a high-pressure compressor blade, (b) cross section of the blade

Following the design procedure, a few eligible blade profiles are analyzed with COROS for various contact configurations. A reduced order model is computed from the $3 \mathrm{D}$ finite element mesh files and contact simulations are run through out a wide angular speed range. For each angular speed, a Fourier spectrum is computed once steady state has been reached. Putting side by side these spectra leads to an interaction map such as the one pictured in Fig. 10. Peaks of amplitude define critical speeds that should be avoided.

\section{Research and development projects and perspectives}

\subsection{Full-scale interaction tests}

As explained in the introduction the study of Rotor/Stator contact is relatively recent at Snecma. First experimental tests were performed in 2006 and the development of the numerical approach took roughly five years. Work is in progress for Snecma and its academic partners in order to improve COROS. Beside of the numerical developments, other academic partners work with Snecma focusing on: (1) understanding and simulating wear mechanism 


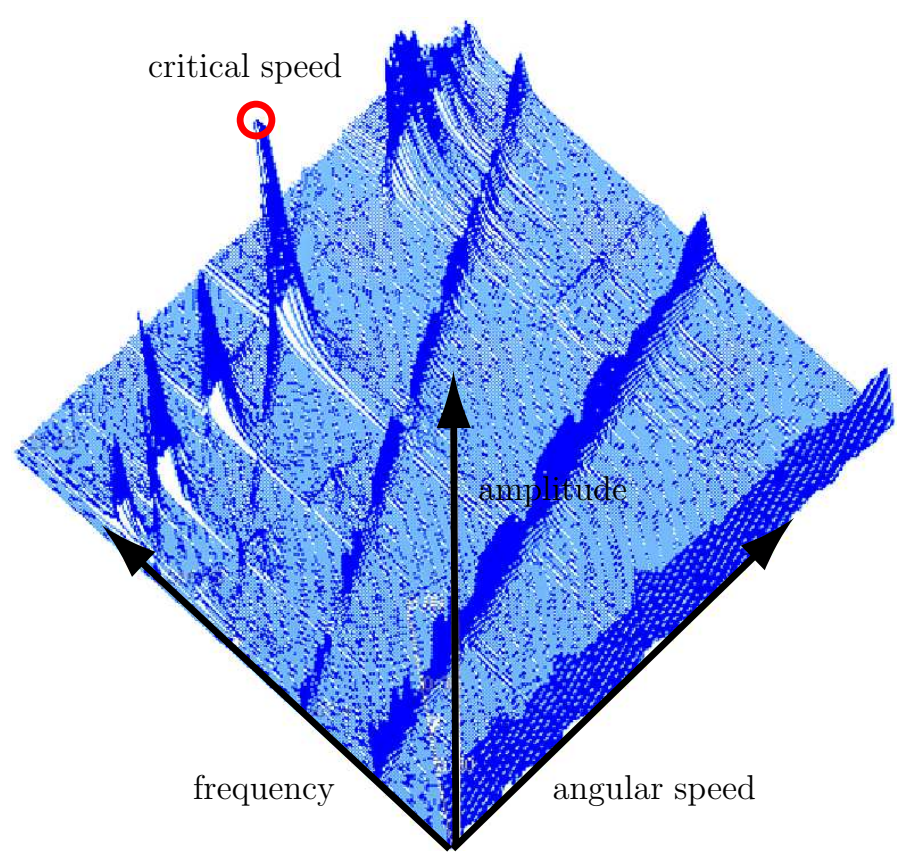

Figure 10. Time-Frequency diagram highlighting critical area defined as a suddenly increasing of frequency amplitude

of abradable coating, (2) studying thermal effects in contact and developping new full-scale interaction tests. The numerical applications in industrial environment show difficulties in matching the tests and the shape of the casing is the first order parameter influencing the dynamic response of blades. The quality of measured temperature data was poor for $\mathrm{SN}_{1}$ and $\mathrm{SN}_{2}$ test benches. A new campaign of three tests is in progress taking into account the aforementioned limitations. The geometry of these three tests is representative of a high-pressure compressor. A longer blade is instrumented with strain gages. Thermocouples are located on the outer side of casing additionally an infrared thermal camera is used to measure the temperature of blades and abradable coating. The casing is initially scanned in order to know its shape with great precision. After the test the casing will be scanned again (ten points axially for each degree along the circumference). The only difference between the first two tests is the geometry of the blisk. The differences of the blade are a small change for the stacking law based on the numerical investigations mentioned above regarding blade design optimization. The targetted speed is slightly different because of the difference of natural frequencies. The difference between the second and third test is the abradable coating. In the second the coating is an aluminum-silicon with polyester whereas the other has only a metallic matrix composed of aluminum-silicon. This work will constitute a rich test plan to improve COROS.

\subsection{Wear modeling improvements}

The modeling of wear in COROS is clearly a stringent limit. The material parameters: yield stress, plastic modulus and young modulus provide accurate contact forces on the blade but additional phenomena must be accounted for in order to match experimental observations. However an introduction of viscosity for the elastic behavior improves the model slightly [12]. A qualitative study based on a phenomenological approach is employed to take into account wear mechanisms such as: erosion, densification, plasticity, cutting, smearing or material transfer [13]. The new law is an addition of terms representing each wear mechanism. The coding in COROS is in progress. Important work will be done in order to match experimental tests performed in French universities. A first test bench, see Fig. 11 and Fig. 12, is also performed in order to characterize the contact forces between abradable and a

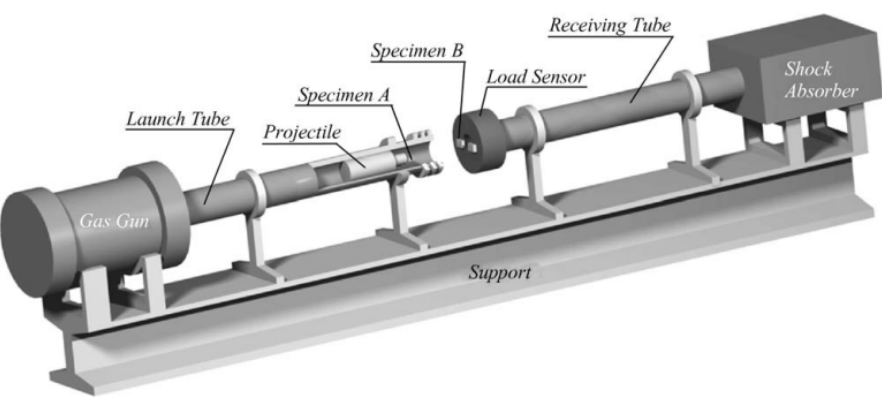

Figure 11. Test bench developed in partnership with Snecma to measure contact under high velocity $(300 \mathrm{~m} / \mathrm{s})$ [12]

titanium tool [14]. This test bench has been improved in order to measure axial, tangential and radial forces and to put a camera in-situ. These tests are very interesting to calibrate the abradable behavior in COROS since there is no dynamics movement for the titanium tool. So the numerical simulations are more or less fast and easy. A different test platform consists of a rotating cylin-

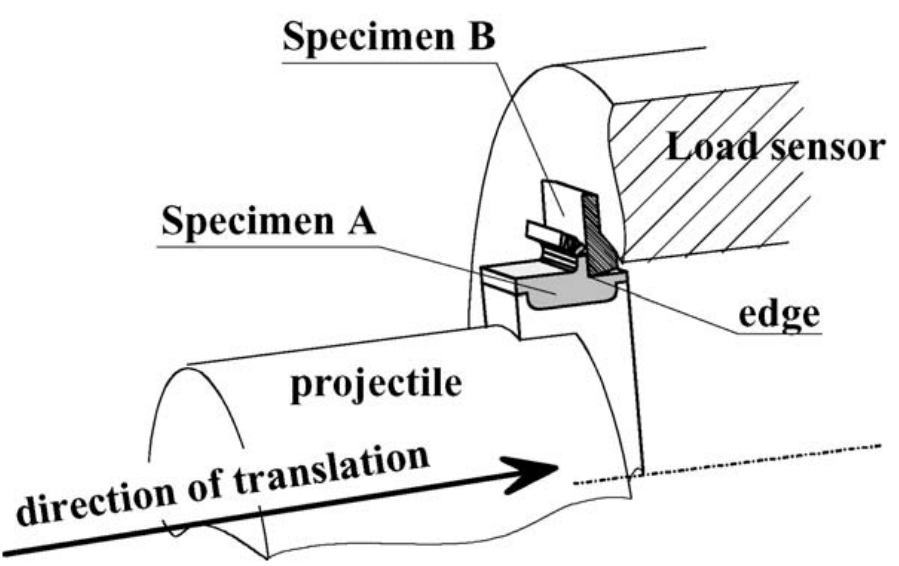

Figure 12. Detailed view of the projectile and the titanium tool on the test bench [14]

der whose external surface is coated with an abradable material, see Fig. 12. The blade geometry has been simplified and the interaction generated by translating the blade toward the rotating cylinder [15]. The numerical simulations of this test can settle the abradable parameters and also the contact parameters since the dynamic behavior is precisely measured through digital image correlation and strain gages.

\subsection{Introduction of thermal effects}

The full-scale interaction tests have shown significant increase of temperature. Then some publications highlight the influence of thermal effects through numerical approach [16, 17]. For the new test benches, tests will be performed in order to measure the temperature during a blade/abradable contact. For example Infrared thermal camera will measure temperature of the coating. Thermocouples stuck on the blade, through an inverse method, will provide temperature on the contact (on the blade tip). The associated numerical approach is still in consideration, notably on the manner to take into account the thermal expansion.

\subsection{Advanced signal processing techniques}

A third evolution of COROS aims at improving the Fourier analysis of the vibratory movement of the blade as detailed in [18]. The displacement of the blade may not always be periodic and a usual Fourier analysis may thus be inefficient. The analysis of time responses is here expanded to transient time responses based on a modified Empirical Mode Decomposition (EMD) procedure [19, 


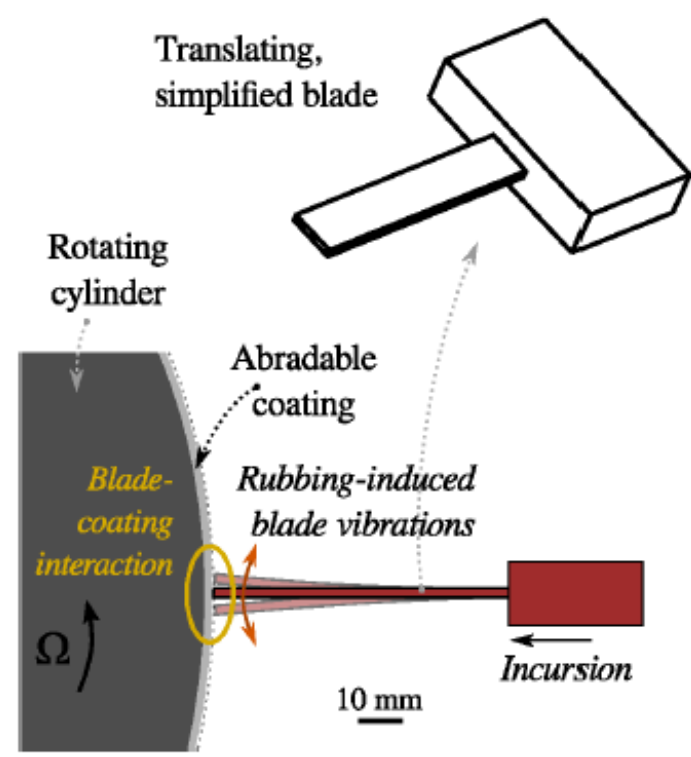

Figure 13. Schematic representation of the test bench developed to study the interaction forces [15]

20]. Signal is decomposed over a basis of Intrinsic Mode Functions (IMF). The IMF functions, under certain mathematical properties [19] are associated with instantaneous frequency - obtained with a Hilbert transform of the IMF. Such strategy seems promising for both live monitoring and numerical results post-processing purposes.

\subsection{Full bladed disk interaction analysis}

Both test benches $\mathrm{SN}_{1}$ and $\mathrm{SN}_{2}$ featured full bladed disks but the actual witnessed interaction phenomena only involved a single blade: vibration levels on the casing as well as on the other blades were found negligible experimentally. However, other interaction phenomena exist, such as modal interaction [2] and whirl motions [21], that involve the full bladed disk and the surrounding casing. This section focuses on the extension of COROS to these phenomena. The modal interaction is related to the specific modal

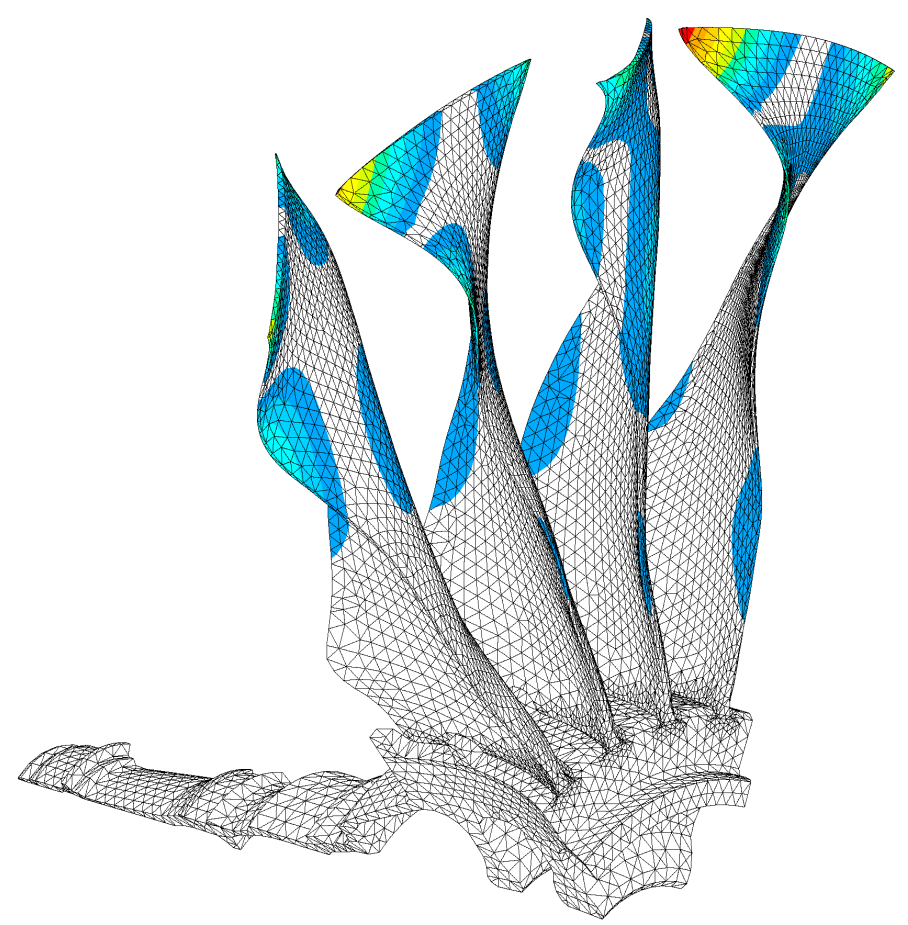

Figure 14. Finite Element Model of 4 sectors of fan stage and its associated displacement field properties of cyclically symmetric structures and may occur when the mode shape geometry of the bladed disk and the casing match and their travelling wave speeds coincide.

First of all, the use of cyclic symmetry conditions, assuming the bladed disks are perfectly tuned, allows for the computation of reduced-order models of full 3D finite element models of bladed disks. Contact simulations are run managing contact on the tip of each blade and displacement fields may be retreived as pictured in Fig. 14 where four sectors of a 22 sector fan stage model are pictured. For each time step of the simulation, the computation of stress fields advantageously provide information regarding critical areas within the structure when contacts occur. For example, a zoom over the stress fields within the blade roots of the aforementioned four sectors is provided in Fig. 15

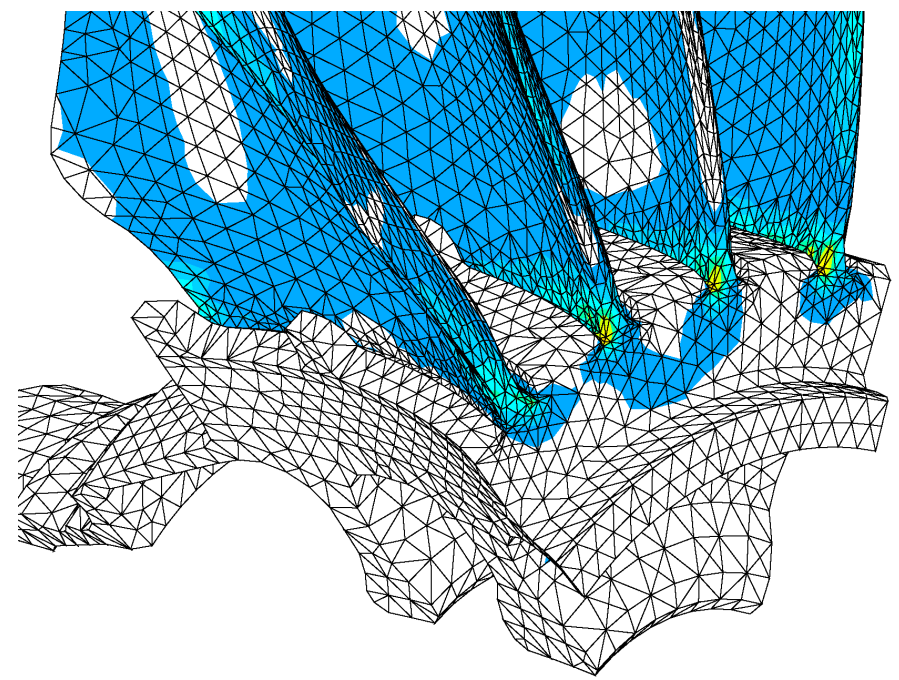

Figure 15. Finite Element Model of the 4 sectors focused on stress field near the dovetail

Accounting for a flexible casing is the last step before the simulation of modal interaction. Exemplarily, a cut view of the fan stage of an aircraft engine and the associated casing is pictured in Fig. 16. For such simulations, more advanced numerical developments featuring a nonlinear contact detection algorithm and the contact surface smoothing are required.

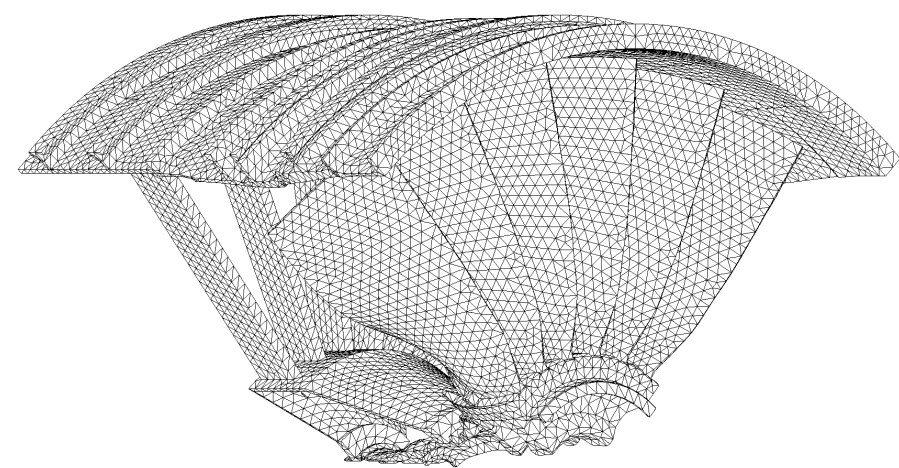

Figure 16. Finite Element Model of a CFM fan stage, with the casing

The whirl/whip phenomenon [3] is also a concern for Snecma. It is a singular issue since under unidentified conditions the fan blades rubs slightly with the casing. Then the contact forces between blades and casing increase up to a point where the damages of the structure may be significant. As a result, the whole shaft features a dynamic movement leading potentially to important damages which could be more important than a Fan Blade Out event. To better understand these phenomena, rarely observed experimentally, the previous numerical approach (flexible casing 
and full bladed disk) has to be coupled with the standard studies of rotor dynamics. In rotor dynamics, studies aim at investigating the movement of flexible shaft using simplified models like cylinder/cylinder contact $[22,23]$. In this context a recent analysis on an Industrial Whole Engine Model (WEM) has included a flexible casing [24] and an other analysis introduces flexible blades through Euler-Bernoulli beams [25]. The objective, now is to perform analyses with COROS for flexible shaft and bearing stiffness. A first attempt was proposed [26] consisting of a 2D in-plane model. This model features a set of curved beams for the casing and beams for the bladed-disk (Figure 17). The flexibility of the shaft is reflected by two linear springs attached to the center node of the disk.

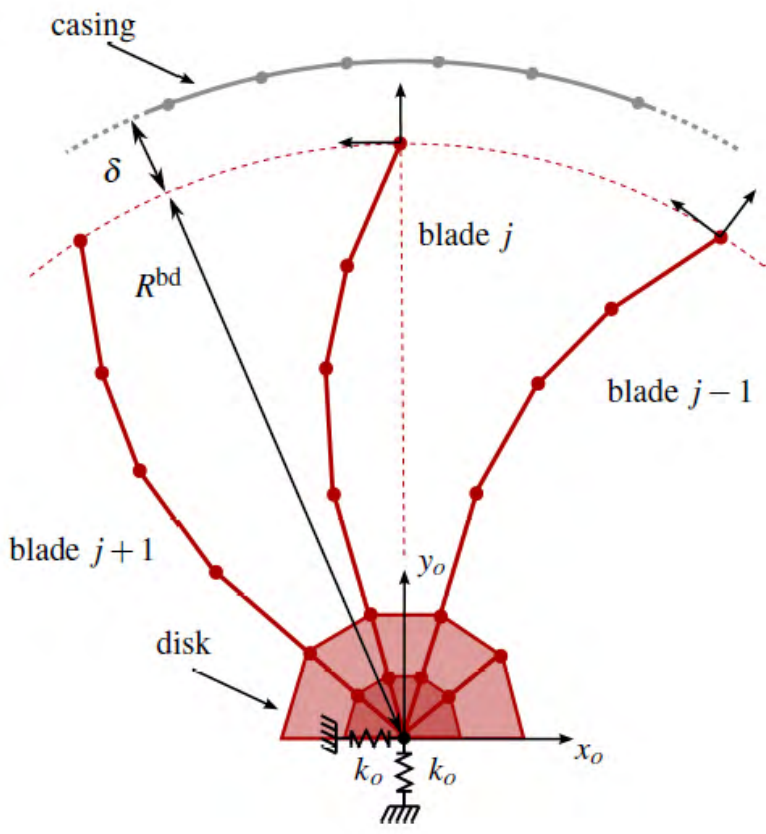

Figure 17. Schematic representation of the 2D in-plane model [26]

\section{Conclusion}

This paper aims at describing the overall methodology deployed at Snecma in order to develop new generation of aircraft engines with reduced operating clearances between rotor and stator. The methodology is twofold, it relies on: (1) an experimental approach to understand phenomena and, (2) a numerical approach for the development of predictive models. The experimental test benches highlight strong links between the wear pattern and the dynamic behavior of the blade, notably the number of lobes observed around the casing is in agreement with the targetted engine order H6 for $\mathrm{SN}_{1}$ and $\mathrm{H} 22$ for $\mathrm{SN}_{2}$. Furthermore, significant increases of temperature are recorded involving thermal effects at the area of contact. The numerical strategy, namely COROS, has been developed for about ten years in partnership with academic partners. The goal of the numerical approach is to simulate a rotating blade in contact with a rigid casing-possibly not perfectly circularand accounts for the abradable coating. To reduce the number of degrees of freedom a first step is to use component mode synthesis methods. The second step is the simulation of blade/casing contact, taking into account the abradable wear. The contact algorithm is an explicit time scheme. This numerical approach is used to simulate the test bench presented in the first section with attractive results in terms of dynamical behavior and wear pattern matching. As a consequence COROS is a numerical tool used in design office in order to discriminate 'bad' blade geometries for which peaks of amplitudes are numerically predicted over the nominal angular speed range. Obviously, various scientific works are in progress since this research field is still fairly recent and the numerical approaches must reach higher predictivity level. Accordingly, a new experimental test plan has been defined with more accurate measures of casing shape. In order to clearly define the influence of each parameter there are few differences between tests. The wear behavior law of the abradable is improving in order to introduce more physical behavior of the abradable in COROS. Then this new law will be used and is expected to match the experimental results. Other scientific works will help Snecma to better apprehend physical phenomena as modal interaction and whirl movements. The introduction of flexible casing and a multi-bladed simulation is a way to study the first issue. For the second one, the way is to couple the COROS approach with a model shaft.

\section{References}

[1] C. Padova, J. Barton, M. Dunn, and S. Manwaring. "Experimental Results From Controlled Blade Tip/Shroud Rubs at Engine Speed". Journal of Turbomachinery 129.4 (2007), pp. 713-723. DOI: 10.1115/1.2720869.

[2] P. Schmiechen. "Travelling wave speed coincidence". $\mathrm{PhD}$ thesis. College of Science, Technology and Medicine, London, UK, 1997.

[3] D.W. Childs and A. Bhattacharya. "Prediction of dry-friction whirl and whip between a rotor and a stator". Journal of Vibration and Acoustics 129 (2007), pp. 355-362. DOI: $10.1115 / 1.2731412$.

[4] L. Prchlik and S. Sampath. "Effect of the microstructure of thermally sprayed coatings on friction and wear response under lubricated and dry sliding conditions". Wear 262.1-2 (2006), pp. 11-23. DOI: 10.1016/j.wear.2006.03.042.

[5] R. K. Schmid. "New high temperature abradables for gas turbines". PhD thesis. Zurich, Switzerland: Swiss Federal Institute of Technology, 1997.

DOI: 10.3929/ethz-a-001809249.

[6] A. Millecamps, J.F. Brunel, P. Dufrénoy, F. Garcin, and M. Nucci. "Influence of thermal effects during blade-casing contact experiments". Proceedings of the ASME IDETC/CIE. DETC2009-86842. San Diego, USA, Sept. 2009.

DOI: 10.1115/DETC2009-86842. OAI: hal-01223060.

[7] M. Legrand, A. Batailly, B. Magnain, P. Cartraud, and C. Pierre. "Full three-dimensional investigation of structural contact interactions in turbomachines". Journal of Sound and Vibration 331.11 (2012), pp. 2578-2601.

DOI: $10.1016 /$ j.jsv.2012.01.017. OAI: hal-00660863.

[8] N. Carpenter, R. Taylor, and M. Katona. "Lagrange constraints for transcient finite element surface contact". International Journal for Numerical Methods in Engineering 32 (1991), pp. 103-128. DOI: $10.1002 / \mathrm{nme} .1620320107$.

[9] M. Legrand, A. Batailly, and C. Pierre. "Numerical investigation of abradable coating removal through plastic constitutive law in aircraft engine". Journal of Computational and Nonlinear Dynamics 7 (2011)

DOI: 10.1115/1.4004951. OAI: hal-00627526.

[10] A. Batailly, M. Legrand, A. Millecamps, and Garcin F. "Numericalexperimental comparison in the simulation of rotor/stator interaction through blade-tip/abradable coating contact". Journal of Engineering for Gas Turbines and Power 134 (2012). DOI: 10.1115/1.4006446. OAI: hal-00746632.

[11] A. Batailly, M. Legrand, A. Millecamps, S. Cochon, and F. Garcin. "Redesign of a high pressure compressor blade accounting for nonlinear structural interactions". Proceedings of the ASME Turbo Expo Conference. GT2014-25673. Düsseldorf, Germany, June 2014. DOI: 10.1115/GT2014-25673. OAI: hal-01120158. 
[12] A. Batailly, M. Cuny, M. Legrand, and S. Philippon. "Numericalexperimental confrontation in the simulation of tool/abradable material interaction". Journal of Engineering for Gas Turbines and Power 135 (2013). DOI: 10.1115/1.4023262. OAI: hal-01200677.

[13] M.O. Borel, A.R. Nicoll, H.W. Schlapfer, and R.K. Schmid. "The wear mechanisms occurring in abradable seals of gas turbines". Surface and Coatings Technology 39 (1989), pp. 117-126. DOI: 10.1016/0257-8972(89)90046-7.

[14] G. Sutter, S. Philippon, and F. Garcin. "Dynamic analysis of the interaction between an abradable material and a titanium alloy". Wear 261.5-6 (2006), pp. 686-692. DOI: 10.1016/j.wear.2006.01.030. OAI: hal-01223431.

[15] R. Mandard, J.-F. Witz, X. Boidin, J. Fabis, Y. Desplanques, and J. Meriaux. "Interacting force estimation during blade/seal rubs". Tribology International 82, Part B (2014), pp. 504-513. DOI: 10.1016/j.triboint.2014.01.026. OAI: hal-01081384.

[16] A. Muszynska. "Rotor-to-stationary part full annular contact modeling". The 9th International Symposium on Transport Phenomena and Dynamics of Rotating Machinery. Honolulu, USA, 2002.

[17] A. Millecamps. "Interaction aube/carter: contribution de l'usure de l'abradable et de la thermomécanique sur la dynamique d'aube". $\mathrm{PhD}$ thesis. Université de Lille, 2010. OAI: tel-01200536.

[18] A. Batailly and M. Legrand. "Conjectural Bifurcation analysis of an aircraft engine blade undergoing 3D unilateral contact constraints". Proceedings of the ASME Turbo Expo Conference. GT2014-25674. Düsseldorf, Germany, June 2014. DOI: 10.1115/GT2014-25674. OAI: hal-01223575.

[19] N.E. Huang, Z. Shen, S.R. Long, M.C. Wu, H.H. Shih, Q. Zheng, N.-C. Yen, C.C. Tung, and H.H. Liu. "The empirical mode decomposition and the Hilbert spectrum for nonlinear and non-stationary time series analysis". Proceedings of the Royal Society of London A: Mathematical, Physical and Engineering Sciences 454.1971 (1998), pp. 903-995.

DOI: $10.1098 /$ rspa.1998.0193.
[20] J.S. Smith. "The local mean decomposition and its application to EEG perception data”. Journal of the Royal Society Interface 2.5 (2005), pp. 443-454.

DOI: 10.1098/rsif.2005.0058.

[21] S.K. Sinha. "Rotordynamic analysis of asymmetric turbofan rotor due to fan blade-loss event with contact-impact rub loads". Journal of Sound and Vibration 332.9 (2013), pp. 2253-2283. DOI: 10.1016/j.jsv.2012.11.033.

[22] M. Cole. "On stability of rotordynamic systems with rotor-stator contact interaction". Proceedings of the Royal Society of London A: Mathematical, Physical and Engineering Sciences 464.2100 (2008), pp. 3353-3375. DOI: $10.1098 /$ rspa.2008.0237.

[23] A. Muszynska. "Rotor-to-stationary element rub-related vibration phenomena in rotating machinery: Literature survey". The Shock and Vibration Digest 21.3 (1989), pp. 3-11. DOI: $10.1177 / 058310248902100303$.

[24] E. P. Petrov. "Multiharmonic analysis of non linear whole engine dynamics with bladed disk-casing rubbing contact". Proceedings of the ASME Turbo Expo Conference. GT2012-68474. Copenhagen, Denmark, June 2012. DOI: $10.1115 / G T 2012-68474$.

[25] M.-O. Parent, F. Thouverez, and F. Chevillot. "Whole Engine Interaction in an bladed rotor-to-stator contact". Proceedings of the ASME Turbo Expo Conference. GT2014-25253. Düsseldorf, Germany, June 2014. DOI: 10.1115/GT2014-25253. OAI: hal-01223063.

[26] N. Salvat, A. Batailly, and M. Legrand. "Two-dimensional modeling of shaft precessional motions induced by blade/casing unilateral contact in aircraft engines". Proceedings of the ASME Turbo Expo Conference. GT2014-25688. Düsseldorf, Germany, June 2014. DOI: 10.1115/GT2014-25688. OAI: hal-01090671. 